\title{
Effect of informal care on health care utilisation for the elderly in China: Evidence from China Health and Retirement Longitudinal Study (CHARLS)
}

\section{Xinlan Chen}

Huazhong University of Science and Technology Tongji Medical College https://orcid.org/0000-00034231-9936

\section{Dai Su}

Huazhong University of Science and Technology Tongji Medical College

\section{Xinlin Chen}

Huazhong University of Science and Technology Tongji Medical College

Yingchun Chen ( $\nabla$ chenyingchun@hust.edu.cn )

Huazhong University of Science and Technology

\section{Research}

Keywords: Informal care, Health care utilization, Rural China

Posted Date: May 19th, 2021

DOl: https://doi.org/10.21203/rs.3.rs-522166/v1

License: (c) (i) This work is licensed under a Creative Commons Attribution 4.0 International License. Read Full License 


\section{Abstract}

\section{Background}

Receiving informal care from family members is the mainstream way of care for the elderly in China because of the influence of the culture of filial piety. However, the relationship between informal care and health care use in urban and rural areas needs to be further explored. This study aimed to understand the effect of informal care on health care utilisation for the elderly and explore how this effect differ between urban and rural China.

Method

A total of 5704 residents aged 65 years and above were selected from the wave 3 (2015) and wave 4 (2018) of the China Health and Retirement Longitudinal Study, which is a nationally representative survey. A negative binomial regression model for panel data was used to explore the relationship between informal care and health care utilisation. Besides, a fixed-effect binary choice model for panel data was used for sensitivity test.

Result

The elderly who received informal care had an increase in outpatient and inpatient visits compared with those who did not receive. The inpatient visits of the elderly who received 15-29 days of informal care was higher (incidence rate ratio $[I R R]=2.082, P<0.05$ ). In addition, the elderly who received informal care for more than 30 days had $39.6 \%$ more inpatient visits (IRR $=1.396, P<0.01)$ and $37.4 \%$ more outpatient visits than the elderly who did not receive informal care $(I R R=1.374, P<0.05)$. For urban respondents, receiving informal care can facilitate outpatient use of the elderly, but for rural respondents, receiving informal care can predict an increase in outpatient and inpatient visits.

\section{Conclusion}

The impact of informal care on health care utilisation varies between rural and urban residents. Relevant departments should pay attention to the differences in the medical service utilisation amongst different elderly groups and gradually reduce the medical inequality of the elderly.

\section{Background}

Along with global ageing, China has stepped into the ageing society since 2000 , and China's ageing process is much faster than those of other low- and middle-income countries. According to the results of the seventh census, $13.8 \%$ of the population is over 65 years old in 2020 [1]. However, over $17 \%$ of the elderly population should be in the hospital but fail to be hospitalised [2]. Unlike developed countries, China, as a developing country, has not effectively met the medical service needs of the elderly (especially the elderly in rural areas) [3, 4]. Informal care provided by relatives, such as children and spouses, is currently the most mainstream way of care in China because of the culture of filial piety. Filial piety is a 
core value of Confucianism in Chinese culture and has a strong influence; thus, many Chinese elderly will not choose to move into nursing homes [5]. China's recent documents clearly supported the continuous improvement of home-based, community-based, institutional-based and integrated elderly care service systems promote the health of the elderly and the development of the elderly care industry [6, 7]. However, informal care will still be an important part of China's long-term care system for some time.

Prior studies on informal and formal care do not definitively establish whether the two types of care are substitutes or complements. Some studies found through carefully testing and controlling for endogeneity that informal care by children is a net substitute for long-term care, such as home health care and nursing home care, as well as for hospital care and physician visits [8,9]. Furthermore, the care provided by children can reduce the expenditure on health services for the elderly; hence, informal care has an alternative effect on health care utilisation [10]. However, the substitution may only be reflected in the elderly with certain diseases, such as diabetes [11]. Prior studies also showed that informal care by adult children can decrease low-skilled home care use (paid domestic help) and is a complement to highskilled home care (nursing/personal care) in Europe [12]. Accepting the care provided by family members can improve the use of outpatient and hospitalisation by the elderly, especially for those over 75 years old [13]. As China's ageing population continues to increase, policies that encourage informal care can effectively reduce the elderly's demand for housekeeping services, nursing homes and hospital outpatient clinics. This provides a solution for China's pension problems [14].

Rural and urban China represent two distinctive classes. For instance, compared with their urban counterparts, rural residents are more likely to be farmers with lower levels of education and income [15]. Urban and rural areas have great differences in family structure. The children of urban families visit their parents more conveniently and more frequently, whereas the children of rural families only meet with their parents on festivals due to distance issues [16]. Moreover, the accessibility of health services for the elderly in rural areas is worse than that in urban areas [17]. In this case, the scarcity of studies that investigated the patterns of informal care and their association with formal care by considering ruralurban disparity warrants the identification of the relationship in the specific rural and urban contexts to improve the validity of findings.

Our study extends the literature by examining how informal care affects the frequency of outpatient and inpatient use of the elderly in urban and rural China by using negative binomial regression for panel data and considering the total days of informal care provided by all family members. We need to understand the relationship between informal care and health care utilisation to promote the healthy development of the long-term care system for the elderly and meet the needs of the elderly for the utilisation of health services. This research answers the following three questions: Is informal care positively or negatively associated with health care utilisation? How does different care time affect the frequency of inpatient and outpatient visits for the elderly? Is there a difference in this effect between China's urban and rural areas?

\section{Method And Material}




\section{Conceptual model}

This study is based on the Andersen and Newman Framework of Health Service Utilisation. The Andersen model is used in analysing the factors that affect health service utilisation (including hospitalisation, doctor visits, dental care, etc.). The initial Andersen model includes predisposing characteristics, enabling resources and needs [18]. Amongst them, predisposing characteristics refer to the demographic characteristics, social structure and health beliefs of the population who tend to use medical services before the occurrence of a disease. Enabling resources refer to the individual's ability to obtain medical services and the accessibility of medical service resources. Need refers to the direct factors of health service utilisation, including perceived illness measures and evaluated illness measures $[19,20]$. The revised Andersen model believes that individual medical behaviour is the result of the interaction of contextual characteristics, individual characteristics and medical results. Since its creation, the Anderson model has been widely used in researches related to health expenditures and health service utilisation and is therefore an authoritative research model for medical and health services [20,21]. Thus, this study selected variables based on this model. In addition, informal care provided by family members was incorporated into the regression model as an enabling component by referring to the practices of previous literatures [22].

\section{Data and Sample}

The data used in this study were derived from the China Longitudinal Study of Health and Retirement (CHARLS). CHARLS is a national survey aimed at providing comprehensive and high-quality data, such as demographic background, family characteristics, health behaviours and conditions and retirement information, of residents aged 45 years and older. A multi-stage stratified proportional probability sampling design was used to randomly select households from 450 villages and residential communities in 150 counties and regions in 28 provinces [23]. The wave 3 study conducted in 2015 and the wave 4 study in 2018 were used for analysis in this paper. A balanced panel data with 5704 participants was formed according to the following criteria: 1) 65 years and older and 2) information about outpatient, hospitalisation and family care were provided in both waves. The details of the sampling process are shown in Fig. 1. The respondents were categorised as urban and rural residents according to the family residential area defined by the National Bureau of Statistics of China.

\section{Dependent variables}

This paper analysed two types of health care utilisation: outpatient and inpatient services. The respondents were asked about how many times they had been visited by medical institutions in the last month and how many times they had received inpatient care during the past year. Outpatient and inpatient visits were used to evaluate the utilisation of health services in the elderly in this study. Besides, 
the dichotomous variable, namely, whether or not the participants use outpatient or inpatient services, was also used to examine health service utilisation.

\section{Key variables}

Interviewees were asked who helped them with their daily life activities in CHARLS. The 10 options for this question are: a) Spouse; b) Father, Mother, Father-in-law or Mother-in-law; c) Children, Children's spouses, Grandson or Granddaughter; d) Sibling, Brother-in-law, Sister-in-law, Sibling of spouse, Children of sibling, Brother-in-law of spouse, Sister-in-law of spouse, Children of brother-in-law or Children of sisterin-law; e) Other relatives; f) Paid helper (such as nanny); g) Volunteer; h) Employee(s) of facility; i) Community; j) Others. The participants who selected one or more of options a-e were considered to have accepted informal care from family members $[13,14]$. In addition, the interviewees were asked about the number of days in the past month that family members had assisted them.

In this research, informal care was examined by two aspects:

a) Whether the respondents have received informal care from family members. The answers were coded as 'Yes' and 'No.'

b) The number of days of informal care that respondents received in a month. The answers were coded as 'none,' 'less than 15 days,' 'between 15 and 29 days' and '30 days or more.'

\section{The Control variables}

Control variables were selected in accordance with predisposing characteristic, enabling resources and needs according to the Andersen model [24-27]. The following individual-level characteristics were considered as control variables (Table 1).

Table 1: Definition/codes of the control variables. 


\begin{tabular}{|c|c|c|}
\hline & Variables & Codes/definition \\
\hline \multirow{4}{*}{$\begin{array}{l}\text { Predisposing } \\
\text { Characteristics }\end{array}$} & Gender & $0=$ Male; $1=$ Female \\
\hline & Age & Continuous variable \\
\hline & $\begin{array}{l}\text { Marital } \\
\text { statues }\end{array}$ & $0=$ Single; $1=$ Partnered \\
\hline & Education & $\begin{array}{l}1=\text { Illiterate; } 2=\text { Primary school and lower; } 3=\text { Junior middle } \\
\text { school; } 4=\text { = Senior middle school and higher }\end{array}$ \\
\hline \multirow[t]{5}{*}{$\begin{array}{l}\text { Enabling } \\
\text { Resources }\end{array}$} & $\begin{array}{l}\text { Medical } \\
\text { insurance }\end{array}$ & $0=$ None; $2=$ Yes \\
\hline & Pension & Whether received any pension or not: $1=\mathrm{No} ; 2=\mathrm{Yes}$ \\
\hline & $\begin{array}{l}\text { Financial } \\
\text { support from } \\
\text { children }\end{array}$ & $\begin{array}{l}\text { Financial support received from children: } 0=\text { None; } 1=0-2000 \text { yuan; } \\
2=2000-5000 \text { yuan; } 3=5000-10000 \text { yuan; } 4=10000 \text { yuan or more }\end{array}$ \\
\hline & Smoke & $0=\mathrm{No} ; 2=\mathrm{Yes}$ \\
\hline & Drink & $0=\mathrm{No} ; 2=\mathrm{Yes}$ \\
\hline \multirow[t]{5}{*}{ Need } & $\begin{array}{l}\text { Chronic } \\
\text { diseases }\end{array}$ & $0=$ None; $1=$ Yes \\
\hline & $\begin{array}{l}\text { Number of } \\
A D L \\
\text { limitations }\end{array}$ & Range from 0 to 6 \\
\hline & $\begin{array}{l}\text { Number of } \\
\text { IADL } \\
\text { limitations }\end{array}$ & Range from 0 to 6 \\
\hline & $\begin{array}{l}\text { Self-rated } \\
\text { health }\end{array}$ & 1 =very good; 2 =good; $3=$ fair; $4=$ =poor; $5=$ very poor \\
\hline & Year & $2015 ; 2018$ \\
\hline
\end{tabular}

Note: ADL: activities of daily living; IADL: instrument activities of daily living.

\section{Statistical analysis}

The dependent variables of this study are outpatient visits and inpatient visits, which are count variables; therefore, the analysis methods considered were Poisson regression and negative binomial regression [28]. However, for a good-fitting model, Poisson regression requires the mean and variance of the dependent variable to be equal. Substantial departures from this measure may indicate a problem with model specification and also suggest that the estimated standard errors may be downwardly biased. In comparison, negative binomial regression is more suitable when overdispersion occurs [29]. This study examined whether the two dependent variables have overdispersal through the likelihood-ratio test of 
alpha value. The results show that the alpha value is significantly not 0 ( $95 \%$ confidence interval [Cl]: 4.75-6.03; 95\% Cl: 1.41-2.09), which means negative binomial regression should be used in this study instead of Poisson regression $[30,31]$. Subsequently, this study conducted Hausman test (both $P<0.001)$ and $L R$ test (both $P<0.001$ ) using inpatient and outpatient visits as the outcome variables, respectively. The results showed that the fixed effect is more applicable. Therefore, fixed-effect negative binomial regression for panel data was conducted to estimate the impact of informal care on the health service utilisation of the elderly. [32]. Cluster-robust standard errors were used to control heteroscedasticity [33]. The specification of the model was as follows:

$\ln \left(\lambda_{i t}\right)=\beta_{1}$ care $_{i t}+\beta_{2} P_{i t}+\beta_{3} E_{i t}+\beta_{4} N_{i t}+\mu_{i t}{ }^{+} \varepsilon$,

where $\lambda_{i t}$ represents the outpatient or inpatient visits of individual $i$ in period $t$, care ${ }_{i t}$ represents the time of informal care obtained by individual $i$ in period $t$, and $P_{i t} E_{i t}$ and $N_{i t}$ represent the control variables related to predisposing characteristics, enabling resources and needs in the Anderson Model, respectively. $\mu_{i t}$ is the individual fixed effect, and $\varepsilon$ is the error term. Incidence rate ratio (IRR) was calculated to facilitate the interpretation of the results. [34].

Model uncertainty is ubiquitous in social science. Thus, substitution dependent variables and substitution regression model were used to test the robustness [35]. The dichotomous variable, namely, whether outpatient and inpatient services were used, was regarded as the outcome variable. A fixed-effect binary choice model for panel data was used for sensitivity test.

\section{Results}

\section{Basic characteristics of the respondents}

The basic characteristics of the whole sample are shown in Table 2. In general, the elderly living in the city have slightly more outpatient visits and lesser inpatient visits than those of the rural elderly.

Table 2: Sample characteristics of the selected respondents at baseline. 


\begin{tabular}{|lllllll|}
\hline & \multicolumn{2}{l}{ All $(\mathrm{N}=5704)$} & \multicolumn{2}{l}{ Urban(N=1427) } & \multicolumn{2}{l|}{ Rural(N=4277) } \\
& mean & Sd. & mean & Sd. & mean & Sd. \\
\hline Inpatient & 0.36 & 0.93 & 0.37 & 0.81 & 0.36 & 0.97 \\
\hline Outpatient & 0.46 & 1.49 & 0.41 & 1.36 & 0.48 & 1.54 \\
\hline Informal care & 1.68 & 1.20 & 1.56 & 1.14 & 1.73 & 1.22 \\
\hline Gender & 0.49 & 0.50 & 0.51 & 0.50 & 0.49 & 0.50 \\
\hline Age & 74.35 & 6.54 & 74.13 & 6.36 & 74.42 & 6.59 \\
\hline Marital status & 0.49 & 0.50 & 0.53 & 0.50 & 0.48 & 0.50 \\
\hline Education & 1.86 & 0.87 & 2.33 & 1.08 & 1.70 & 0.72 \\
\hline Chronic diseases & 0.46 & 0.50 & 0.47 & 0.50 & 0.45 & 0.50 \\
\hline Smoke & 0.26 & 0.44 & 0.20 & 0.40 & 0.27 & 0.45 \\
\hline Drink & 0.29 & 0.46 & 0.30 & 0.46 & 0.29 & 0.45 \\
\hline Medical insurance & 0.92 & 0.26 & 0.94 & 0.24 & 0.92 & 0.27 \\
\hline Number of ADL limitations & 0.62 & 1.19 & 0.44 & 1.02 & 0.68 & 1.24 \\
\hline Number of IADL limitations & 1.23 & 1.56 & 0.74 & 1.38 & 1.12 & 1.61 \\
\hline Financial support & 1.37 & 1.25 & 1.27 & 1.37 & 1.41 & 1.20 \\
\hline Pension & 0.16 & 0.37 & 0.47 & 0.50 & 0.06 & 0.23 \\
\hline Self-rated health & 3.09 & 0.94 & 2.90 & 0.91 & 3.15 & 0.95 \\
\hline
\end{tabular}

Note: $\mathrm{Sd} .=$ standard error

\section{Informal care of the elderly in urban and rural areas}

This study found by comparing informal care in urban and rural areas of China that the proportion of elderly people who received informal care increased from $19.08 \%$ and $28.99 \%$ in 2015 to $24.80 \%$ and $33.29 \%$ in 2018 , respectively. The elderly who had been in care for 30 days or more accounted for the highest proportion. In addition, a higher proportion of rural elderly people received informal care than urban ones in both years (Fig. 2).

\section{Main Results}

The results of the negative binomial regression in Table 3 show that informal care provided by family members remarkably improved the utilisation of outpatient and inpatient services for the elderly. 
Specifically, compared with the elderly who did not receive family care, the inpatient visits of the elderly who received 15-29 days of informal care was higher (IRR $=2.082, \mathrm{P}<0.05)$. In addition, the elderly who received informal care for more than 30 days had $39.6 \%$ more inpatient visits than (IRR=1.396, $P<0.01)$ and $37.4 \%$ more outpatient visits than those who did not receive informal care $(I R R=1.374, P<0.05)$.

Table 3: Impact of informal care on health service utilisation: fixed-effect negative binomial model for panel data.

\begin{tabular}{|c|c|c|c|c|}
\hline & \multicolumn{2}{|c|}{ Inpatient $(\mathrm{N}=5704)$} & \multicolumn{2}{|c|}{ Outpatient $(\mathrm{N}=5704)$} \\
\hline & IRR & $\begin{array}{l}\text { Bootstrap standard } \\
\text { error }\end{array}$ & IRR & $\begin{array}{l}\text { Bootstrap standard } \\
\text { error }\end{array}$ \\
\hline \multicolumn{5}{|l|}{ Informal care (reference: None) } \\
\hline $1-14 d$ & 1.022 & 0.164 & 1.219 & 0.255 \\
\hline $15-29 d$ & $2.082^{\star \star}$ & 0.664 & 1.262 & 0.415 \\
\hline $30 \mathrm{~d}$ or more & $1.396^{\star \star \star}$ & 0.175 & $1.374^{\star \star}$ & 0.189 \\
\hline Gender (reference: male) & 0.583 & 0.202 & 1.044 & 0.263 \\
\hline Age & $1.042^{* \star}$ & 0.020 & $0.944^{\star \star \star}$ & 0.016 \\
\hline $\begin{array}{l}\text { Marital status (reference: } \\
\text { single) }\end{array}$ & $0.632^{* \star}$ & 0.125 & 1.290 & 0.234 \\
\hline Education (reference: illiterate) & 1.105 & 0.113 & 1.038 & 0.088 \\
\hline $\begin{array}{l}\text { Chronic diseases (reference: } \\
\text { None) }\end{array}$ & $1.399^{\star \star \star}$ & 0.109 & 1.111 & 0.085 \\
\hline Smoke (reference: No) & $0.470^{\star * *}$ & 0.081 & 0.869 & 0.158 \\
\hline Drink (reference: No) & $0.720^{\star *}$ & 0.116 & 1.028 & 0.132 \\
\hline $\begin{array}{l}\text { Medical insurance (reference: } \\
\text { None) }\end{array}$ & 1.275 & 0.291 & 1.263 & 0.215 \\
\hline Number of ADL limitations & 1.056 & 0.041 & 1.037 & 0.042 \\
\hline Number of IADL limitations & 1.044 & 0.042 & 0.993 & 0.039 \\
\hline $\begin{array}{l}\text { Financial support (reference: } \\
\text { None) }\end{array}$ & $1.107^{\star \star}$ & 0.044 & 0.939 & 0.039 \\
\hline Pension (reference: None) & 0.911 & 0.147 & $1.331^{*}$ & 0.228 \\
\hline Self-rated health & $1.238^{\star \star \star}$ & 0.071 & $1.267^{\star \star \star}$ & 0.070 \\
\hline Intercept & $0.026^{\star \star \star}$ & 0.036 & 7.624 & 10.204 \\
\hline
\end{tabular}


Note: IRR = incidence rate ratio. $\left.\left(^{*}\right),{ }^{* *}\right),\left({ }^{* * *}\right)$ mean significant level at $10 \%, 5 \%, 1 \%$, respectively. ADL: activities of daily living; IADL: instrument activities of daily living.

The samples were divided into urban and rural residents to test the difference in the impact of informal care on the formal care of the elderly in urban and rural areas. The results in Table 4 show the remarkable differences between urban and rural areas. In terms of inpatient visits, the number of hospitalisation of the elderly in rural areas who received care for 15-29 days and more than 30 days increased by $111.4 \%$ $($ IRR=2.114, $P<0.05)$ and 53.2\% (IRR=1.532, $P<0.01)$, respectively. In terms of outpatient visits, urban elders who received informal care within 15 days had increased outpatient visits (IRR=3.164, $P<0.01)$, whereas the elderly in rural areas need 30 days or longer period of care to increase outpatient visits significantly $(\mathrm{IRR}=1.500, \mathrm{P}<0.05)$.

Table 4: Association between informal care and health service utilisation in urban and rural China.

\begin{tabular}{|c|c|c|c|c|}
\hline & \multicolumn{2}{|c|}{ Urban $(\mathrm{N}=1427)$} & \multicolumn{2}{|c|}{ Rural $(\mathrm{N}=4277)$} \\
\hline & Inpatient & Outpatient & Inpatient & Outpatient \\
\hline \multicolumn{5}{|c|}{ Informal care冈reference: None》 } \\
\hline $1-14 d$ & 0.488 & $3.164^{\star}$ & 1.210 & 1.330 \\
\hline $15-29 d$ & 2.038 & 2.015 & $2.114^{\star \star}$ & 1.227 \\
\hline $30 \mathrm{~d}$ or more & 1.208 & 1.804 & $1.532^{\star \star \star}$ & $1.500^{\star *}$ \\
\hline
\end{tabular}

Note: IRR = incidence rate ratio. All models have controlled variables, including gender, age, marital status, education, chronic diseases, smoke, drink, medical insurance, number of ADL limitations, number of IADL limitations, financial support, pension and self-rated health. $\left(^{*}\right),\left({ }^{* *}\right),\left({ }^{* * *}\right)$ mean significant level at $10 \%$, $5 \%, 1 \%$, respectively.

\section{Sensitivity tests}

This study regarded whether the respondents used outpatient and inpatient services or not as outcome variables to test the robustness of the results. A fixed-effect binary choice model for panel data was selected after Hausman test (both $\mathrm{P}<0.001$ ). The result showed that informal care can remarkably increase the utilisation of outpatient and inpatient services for the elderly. The result is consistent with the outcome of the negative binomial regression model.

Table 5: Impact of informal care on health care utilisation: fixed-effect binary choice model for panel data. 


\begin{tabular}{|c|c|c|c|c|}
\hline & \multicolumn{2}{|c|}{ 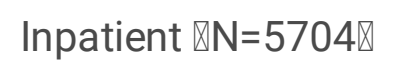 } & \multicolumn{2}{|c|}{ Outpatient $\otimes N=5704 \rrbracket$} \\
\hline & $\beta$ & Sd. & $\beta$ & Sd. \\
\hline \multicolumn{5}{|l|}{ Informal care冈reference: None $\mathbb{Z}$} \\
\hline $1-14 d$ & 0.024 & 0.244 & $0.397^{\star}$ & 0.237 \\
\hline $15-29 d$ & $1.117^{\star \star}$ & 0.441 & 0.298 & 0.406 \\
\hline $30 \mathrm{~d}$ or more & $0.449^{\star *}$ & 0.192 & $0.403^{\star *}$ & 0.184 \\
\hline Gender (reference: male $\mathbb{Z}$ & 1.038 & 1.418 & -0.001 & 0.843 \\
\hline Age & 0.037 & 0.026 & $-0.107^{\star \star \star}$ & 0.027 \\
\hline Marital status (reference: single $\rrbracket$ & $-1.239^{\star \star \star}$ & 0.358 & 0.358 & 0.314 \\
\hline Education (reference: illiterate $\mathbb{Z}$ & 0.054 & 0.124 & -0.089 & 0.149 \\
\hline Chronic diseases (reference: None $\mathbb{Z}$ & $0.407^{\star \star \star}$ & 0.113 & 0.146 & 0.112 \\
\hline Smoke (reference: No囚 & $-0.871^{\star \star \star}$ & 0.268 & $-0.546^{\star \star}$ & 0.270 \\
\hline Drink (reference: No囚 & $-0.370^{\star \star}$ & 0.186 & 0.030 & 0.192 \\
\hline Medical insurance (reference: None》 & 0.364 & 0.232 & 0.227 & 0.235 \\
\hline Number of ADL limitations & $0.112^{*}$ & 0.063 & 0.018 & 0.055 \\
\hline Number of IADL limitations & 0.079 & 0.058 & 0.002 & 0.057 \\
\hline Financial support (reference: None $\mathbb{Z}$ & $0.136^{\star \star}$ & 0.057 & -0.021 & 0.060 \\
\hline Pension (reference: None $\mathbb{Z}$ & -0.180 & 0.250 & 0.144 & 0.262 \\
\hline Self-rated health (reference: very good $\rrbracket$ & $0.236^{\star \star \star}$ & 0.080 & $0.274^{\star \star \star}$ & 0.081 \\
\hline
\end{tabular}

Note: Sd. $=$ standard error. $\left({ }^{\star}\right),\left({ }^{(\star}\right),\left({ }^{\star \star \star}\right)$ mean significant level at $10 \%, 5 \%, 1 \%$, respectively.

\section{Discussion}

\section{Status of informal care and health care utilization}

The proportion of informal care in China is increasing, and the proportion of informal care in rural areas is higher than that in urban areas. The reason may be that Chinese families follow The Pecking Order Theory in their choice of care mode for the elderly, which means that they will use all internal care resources first before social care [36]. 
The elderly living in the city have slightly more outpatient visits and lesser inpatient visits than those of the rural elderly. This finding may be due to the fact that the urban elderly have more convenience to seek medical treatment and more channels to receive outpatient services than the rural elderly [37]. The rural elderly's priority health needs are inhibited by personal economic conditions, especially for diseases with mild symptoms, which reduce their outpatient visits [38]. In addition, mild symptoms may become severe because of the poor economic conditions and poor health literacy of rural elderlies. Therefore, the hospitalisation rate is high in rural areas [39].

\section{Association between informal care and formal care}

This study found that informal care provide by family members is positively associated with outpatient and inpatient services in urban and rural residents. Similar findings were found in prior studies $[12,13$, 40]. Accepting informal care for 15 days or more can remarkably increase the utilisation of health services for the elderly.

In terms of inpatient care, the elderly who receive informal care for 15-29 days per month have more than twice as many inpatient services as those who do not receive care. The hospitalisation rate of the elderly who received informal care for 30 days or more is higher by $39.6 \%$ compared with those who did not receive care. On the one hand, hospitalisation involves highly professional and highly skilled personnel, who cannot be replaced by informal care [12]; on the other hand, family members can detect the diseases of the care recipients in time and help them to seek medical attention promptly.

In terms of outpatient care, the elderly who receive informal care for 30 days or more have higher frequency of outpatient use. The reason may be that informal care provided by family members is more related to daily life care than medical services. Accordingly, caregivers can consult doctors about health status and medical treatment of the elderly to reduce medical barriers. Moreover, the elderly can be sent to medical institutions in time because of the preventive psychology of informal caregivers [41].

\section{Heterogeneity between urban and rural areas}

The impact of informal care on health care utilisation differs greatly between urban and rural areas in China. This finding is in line with prior studies $[42,43]$. The elderly living in cities receive informal care without affecting their inpatient visits. However, in rural areas, receiving care from family members can increase the hospitalisation rate of the elderly. In terms of outpatient use, informal care within 15 days can increase the number of outpatient visits of the urban elderly, and informal care of 30 days or more can increase the outpatient visits of the rural elderly. This difference may be due to the dual socioeconomic structure of urban-rural divide and rule; urban and rural elderly people have differences in income, concepts and service provision [44]. The elderly in rural areas have poor medical awareness and poor economic conditions; therefore, family members have a greater role in urging the elderly to seek medical treatment [37]. Another reason may be the better accessibility of health resources for the urban elderly than that of the rural elderly [17]. The elderly in rural areas, especially the disabled, need help from other family members to obtain outpatient and inpatient services because of the long distance to health care facilities. 


\section{Limitation}

There are three limitations in this study. First, the study period covers only 2 waves. The short study period may not reflect the long-term effects of informal care on health care utilisation. Second, the endogeneity in this study was not controlled which may lead to biased estimates. Third, this study focuses on informal care provided by all the caregivers instead of different caregivers. Further research should be conducted to examine the impact of informal care provided by different caregivers on health care utilisation.

\section{Conclusion}

This study has two main findings. Firstly, informal care provided by family members can remarkably increase the outpatient and inpatient visits of the elderly. Moreover, this effect still exists after replacing the outcome variables and model. Secondly, the association between informal and health care utilisation varies between rural and urban residents. The impact of informal care on the health care use amongst urban elderly is weaker than that in rural areas. These findings imply the role of informal care and remind that relevant departments should pay attention to the differences in medical service utilisation levels amongst different elderly groups and gradually reduce medical inequality amongst the elderly.

\section{Abbreviations}

CHARLS: China Longitudinal Study of Health and Retirement

IRR: incidence rate ratio

Sd.: standard error

ADL: activities of daily living;

IADL: instrument activities of daily living

\section{Declarations}

\section{Acknowledgment}

The authors thank the National School of Development, Peking University and other members for their support and cooperation.

\section{Authors' contributions}

Xinlan Chen and DS designed this study and performed the statistical analysis. XC drafted the manuscript. DS, YC and Xinlin Chen participated in data analysis and helped to revise the draft. All 
authors read and approved the final manuscript.

\section{Funding}

This study was supported by grants from the National Natural Science Foundation of China (71673101 and 71974066).

\section{Ethics approval and consent to participate}

The data used in this study were retrieved from the CHARLS. This survey was endorsed by the Biomedical Ethics Committee of Peking University (NO.IRB 00001052-11015). All participants in the survey signed or marked (if illiterate) the informed consent forms.

\section{Consent for publication}

Not applicable.

\section{Availability of data and materials}

The datasets generated and analysed during the current study are available in the CHARLS repository, [http://charls.pku.edu.cn/en].

\section{Competing interests}

The authors declare that they have no competing interests.

\section{References}

1. National Bureau of Statistics. Main data of the seventh national population census [Internet]. 2021. Available from: http://www.stats.gov.cn/tjsj/zxfb/202105/t20210510_1817176.html

2. Center for Health Statistics and Information. An analysis report of the national health service 2013 [Internet]. Cent. Heal. Stat. Inf. 2016. Available from: http://www.nhc.gov.cn/ewebeditor/uploadfile/2016/10/20161026163512679.pdf

3. Feng Jin, Yangyang Y, Pingyi L. Medical Demand and Growing Medical Costs in China - Based on the Gap bet ween Senior Citizens'Medical Costs in Urban and Rural Areas. Soc Sci China Press. 2015;3:85-103.

4. Jun Y, Chen Y. Do the rural elderly take up more medical resources? Manage World. 2010;5:91-5. 
5. World Health Organization. China country assessment report on ageing and health. [Internet]. 2016. Available from: https://apps.who.int/iris/handle/10665/194271

6. General Office of the State Council of the People's Republic of China. Opinions on promoting the development of elderly care services [Internet]. 2019. p. 1-7. Available from: http://www.gov.cn/zhengce/content/2019-04/16/content_5383270.htm\#

7. General Office of the State Council of the People's Republic of China. Opinions on Promoting the Healthy Development of Elderly Care Services [Internet]. 2020. p. 1-7. Available from: http://www.gov.cn/zhengce/content/2020-12/31/content_5575804.htm

8. Costa-Font J, Jimenez-Martin S, Vilaplana C. Does long-term care subsidization reduce hospital admissions and utilization? J Health Econ [Internet]. Elsevier B.V.; 2018;58:43-66. Available from: https://doi.org/10.1016/j.jhealeco.2018.01.002

9. Van Houtven $\mathrm{CH}$, Norton EC. Informal care and health care use of older adults. J Health Econ [Internet]. 2004;23:1159-80. Available from: https://doi.org/10.1016/j.jhealeco.2004.04.008

10. Van Houtven $\mathrm{CH}$, Norton EC. Informal care and Medicare expenditures: Testing for heterogeneous treatment effects. J Health Econ [Internet]. 2008;27:134-56. Available from: https://doi.org/10.1016/j.jhealeco.2007.03.002

11. Kim Y, Lee M. Effects of Informal Family Care on Formal Health Care: Zero-Inflated Endogenous Count for Censored Response. Heal Econom Data Gr Work Pap. 2011;

12. Bonsang E. Does informal care from children to their elderly parents substitute for formal care in Europe? J Health Econ. 2009;28:143-54.

13. Yangyang Yu, Feng J. Informal care and health care utilization of the ederly. Chinese Econ Q. 2018;17.

14. Lin Wanjuan, Hui W, Zhenpeng Z. Care Selection of Older Adults in China:Informal or Formal Care-Empirical Study Based on the Data of CLHLS and CHARLS. J Shanghai Univ Financ Econ. 2014;16.

15. Gu H, Kou Y, You H, Xu X, Yang N, Liu J, et al. Measurement and decomposition of income-related inequality in self-rated health among the elderly in China 14 Economics 1402 Applied Economics 11 Medical and Health Sciences 1117 Public Health and Health Services 14 Economics 1403 Econometrics. Int J Equity Health. International Journal for Equity in Health; 2019;18:1-11.

16. Fang J. Urban-rural Familiesi the Family Structure Transformation of Suburban Farmers in the Process of Urbanization. Popul Soc. 2020;36:78-89.

17. Li Y, Wu Q, Liu C, Kang Z, Xie X, Yin H, et al. Catastrophic health expenditure and rural household impoverishment in China: What role does the new cooperative health insurance scheme play? PLoS One. 2014;9.

18. Andersen R, Newman JF. Societal and individual determinants of medical care utilization in the United States. Milbank Q. 2005;83:1-28.

19. Andersen R, Newman J. Societal and Individual Determinants of Medical Care Utilization in the United States Author ( s ): Ronald Andersen and John F . Newman Source: The Milbank Memorial 
Fund Quarterly . Health and Society, Vol . 51, No . 1 (Winter, Published by: Wiley o. Milbank Mem Fund Q. 1973;51:95-124.

20. Wang Yiqiao, Wen D, Ren R. Andersen's Health Services Utilization Behavioral Model and Its Evolution. Chinese Heal Econ. 2017;36:15-7.

21. Yue-e L, Shan L. A Review of the Development of the Anderson Model's Theoretical Construction and Analysis Path. Chinese Heal Serv Manag. 2017;18:324.

22. Lu Shan, Baogui D. Studying on The Choice Preferences of Pension Mode among The Urban Ederly in Liaoling Province and Its Influencing Factors Based on Revised Andersen Model. Chinese Heal Serv Manag. 2020;853-8.

23. Yaohui Z, Strauss J, Chen X, Wang Y, Gong J, Meng Q, et al. China Health and Retirement Longitudinal Study Wave 4 User' S Guide. 2020.

24. Heider D, Matschinger $H$, Müller $H$, Saum KU, Quinzler R, Haefeli WE, et al. Health care costs in the elderly in Germany: An analysis applying Andersen's behavioral model of health care utilization. BMC Health Serv Res. 2014;14.

25. Bradley EH, Curry LA, McGraw SA, Webster TR, KasI S V., Andersen R. Intended Use of Informal LongTerm Care: The Role of Race and Ethnicity. Ethn Heal. 2004;9:37-54.

26. Lee SH, Ryu JI, Jung SH. Differences in utilization of medical and dental services among homeless people in South Korea. Int J Environ Res Public Health. 2020;17:1-14.

27. Hajek A, Bertram F, Heinrich F, Rüth V Van, Ondruschka B, Kretzler B, et al. Determinants of health care use among homeless individuals: evidence from the Hamburg survey of homeless individuals. BMC Health Services Research; 2021;1-7.

28. Fields BE, Bell JF, Moyce S, Bigbee JL. The Impact of Insurance Instability on Health Service Utilization: Does Non-metropolitan Residence Make a Difference? J Rural Heal. 2015;31:27-34.

29. Hilbe J. Negative binomial panel models. Cambridge: Cambridge University Press; 2007.

30. Allison PD, Waterman RP. Fixed-effects negative binomial regression models. Sociol Methodol. 2002;32:247-65.

31. Li Mengfei, Wu Zhiyong, Jiang Hua, Xu Congjian, Li Bin, Wu Xin, et al. Analysis of influencing factors of vacancy of special-needed beds in a obstetrics and gynecology hospital based on three-phase panel data. Chinese J Heal Stat. 2020;37:95-7.

32. Chen Qiang. Advanced econometrics and Stata application. Higher Education Press; 2010.

33. Cameron AC, Douglas L Miller. A Practitioner's Guide to Cluster- Robust Inference. J Hum Resour. 2015;50:317-72.

34. Lu HX, Wong MCM, Lo ECM, McGrath C. Risk indicators of oral health status among young adults aged 18 years analyzed by negative binomial regression. BMC Oral Health. 2013;13.

35. Chamberlain G. Binary Response Models for Panel Data: Identification and Information. Econometrica. 2010;78:159-68. 
36. Qingqing Z, Yi Z, Yuyu C. Health Status and Elderly Care: Theory and Evidence from a Randomized Experiment with COPD Patients in China. Econ Res J. 2020;55:36-51.

37. Lu C, Shige Q, Han Z. Outpatient visits and hospitalizations and their associates among communitydwelling older adults in China: 2018. Chin J Public Heal. 2021;37:797-802.

38. Ping G, Jianpeng $C$, Xiaoyuan S. Differences in health status and utilization of health services among the elderly in urban and rural China. Popul Dev. 2005;S1:110-5.

39. Xiangying R, Yongmao W. The Effect of China's New Cooperative Medical Scheme on The Farmers' Medical Behavior Under The Background of Urbanization. Financ Econ. 2015;03:121-30.

40. Gu Yingwen, Yue S. Analysis on the Care Mode Choice for the Disabled Elderly and Its Influencing Factors in China ---Based on the Relationship between Informal Care and Formal Care. Heal Econ Res. 2021;38:54-7.

41. Torbica A, Calciolari S, Fattore G. Does informal care impact utilization of healthcare services? Evidence from a longitudinal study of stroke patients. Soc Sci Med [Internet]. Elsevier Ltd; 2015;124:29-38. Available from: http://dx.doi.org/10.1016/j.socscimed.2014.11.005

42. Zhang Ruli, Mingang L. The Relation between Informal and Formal Care of Disabled Elderly in China -Analysis Based on CLHLS Data. Soc Secur Stud. 2018;6.

43. Zheng Chao, Xuetao C. Informal Care, Medical Expenditure and Life Satisfacation of the Ederly. J Shandong Univ Soc Sci [Internet]. 2020;4:134-45. Available from:

http://marefateadyan.nashriyat.ir/node/150

44. Liu Nina, Yueqing G. A Research on the Change and Influential Factors of the Care Mode of the Elderly in Urban-Rural China---Based on the Social Capital Perspective. China Agric Univ J Soc Sci Ed [Internet]. 2016;33:2. Available from: www.iranesrd.com

\section{Figures}




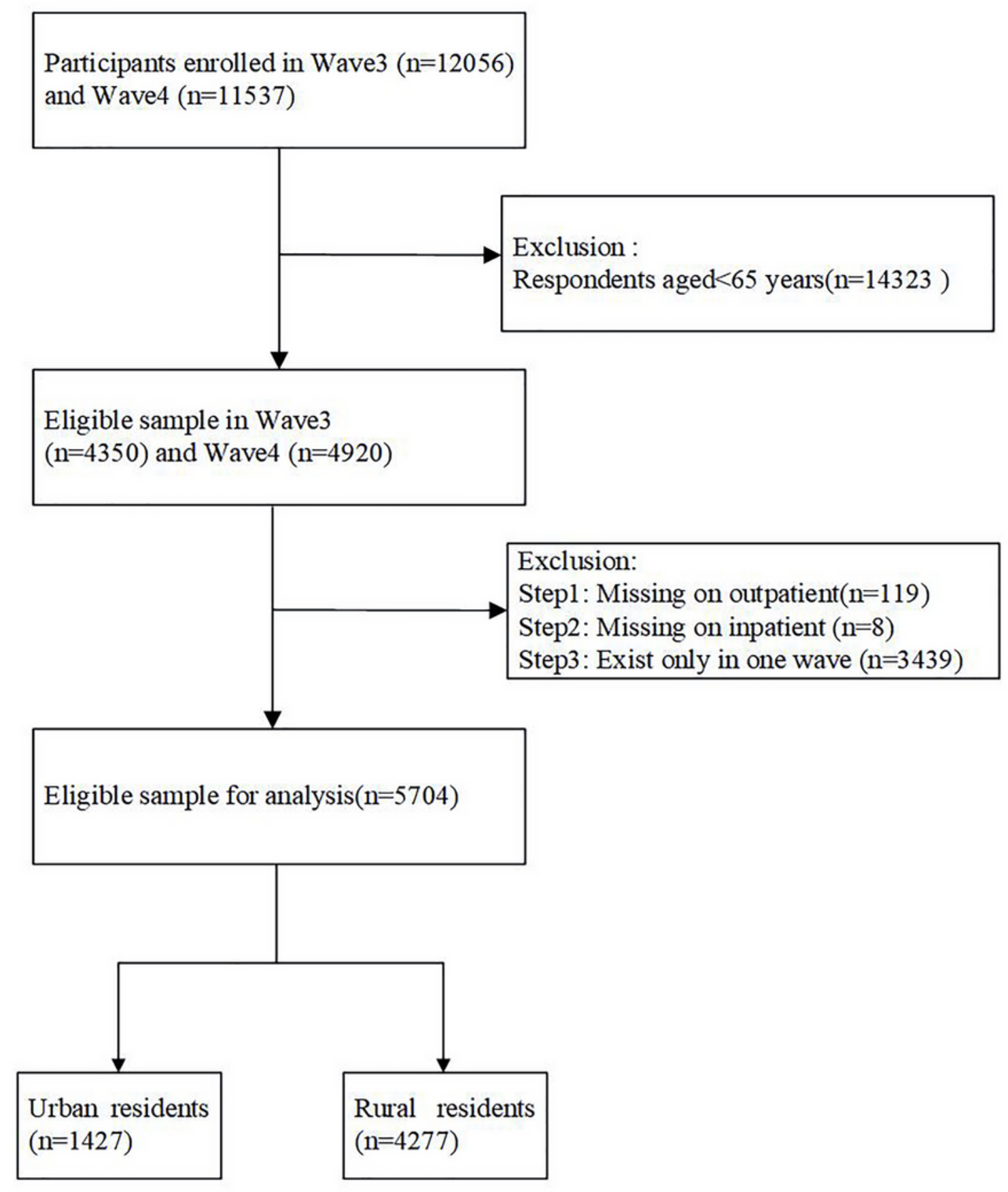

\section{Figure 1}

Flowchart of participant selection. 


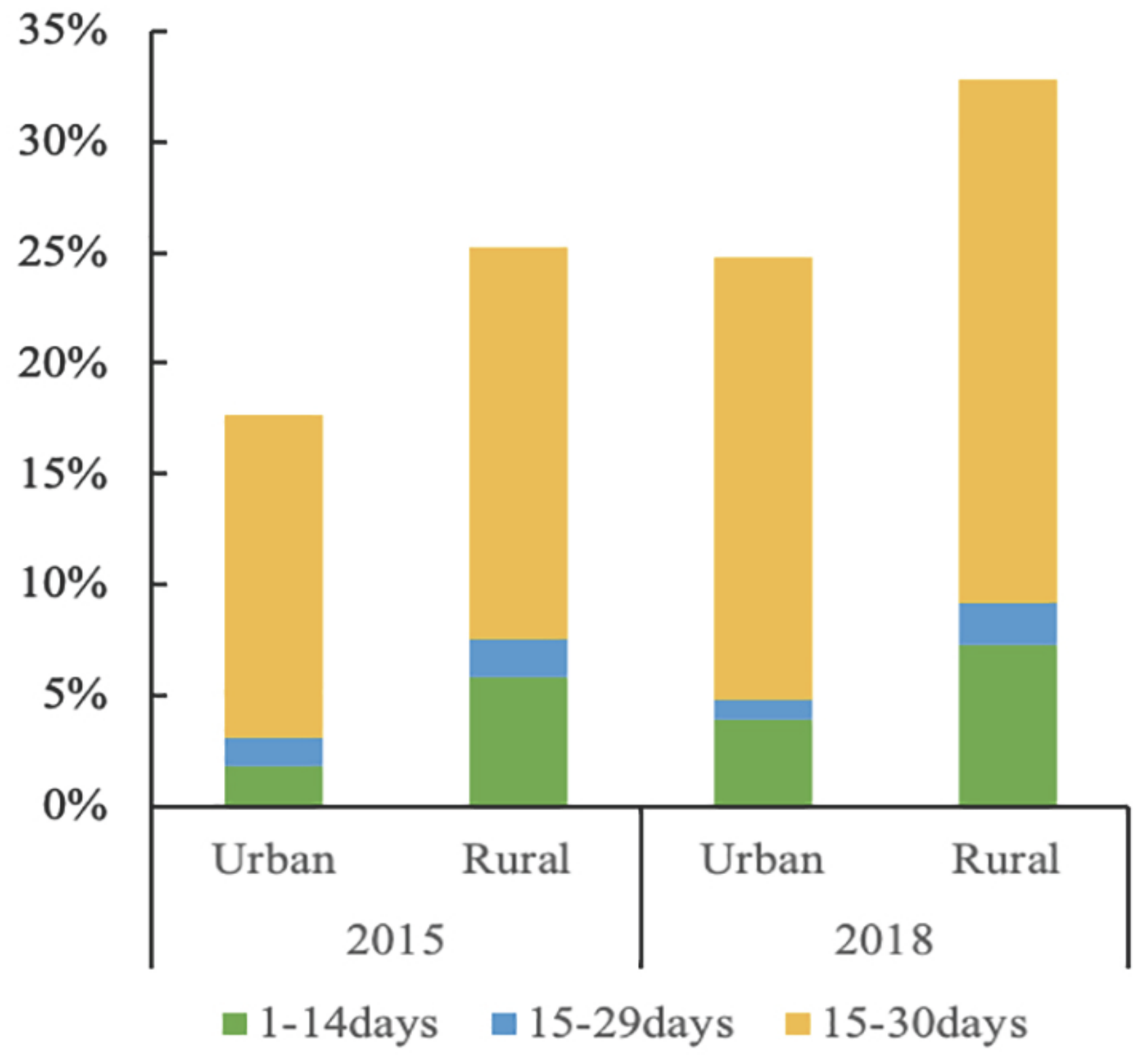

Figure 2

Comparison of informal care in urban and rural areas from 2015 to 2018 